\title{
Simulation and Comparison Between Mid-Holocene and Preindustrial Indian Summer Monsoon Circulation Using a Regional Climate Model
}

\author{
Stefan Polanski ${ }^{*}, 1$, Annette Rinke ${ }^{2}$, Klaus Dethloff ${ }^{2}$, Stephan J. Lorenz ${ }^{3}$, Yongbo Wang ${ }^{2}$ and \\ Ulrike Herzschuh ${ }^{2,4}$
}

\author{
${ }^{1}$ Freie Universität Berlin, Institute for Meteorology, Carl-Heinrich-Becker-Weg 6-10, D-12165 Berlin, Germany \\ ${ }^{2}$ Alfred Wegener Institute for Polar and Marine Research, Research Unit Potsdam, Telegrafenberg A43, 14473 \\ Potsdam, Germany \\ ${ }^{3}$ Max Planck Institute for Meteorology, Bundesstraße 53, D-20146 Hamburg, Germany \\ ${ }^{4}$ Potsdam University, Institute for Earth and Environmental Sciences, Karl-Liebknecht-Straße 24-25, 14476 Potsdam, \\ Germany
}

\begin{abstract}
The regional climate model HIRHAM has been applied over the Asian continent from $0^{\circ} \mathrm{N}$ to $50^{\circ} \mathrm{N}$ and $42^{\circ} \mathrm{E}$ to $110^{\circ} \mathrm{E}$ to simulate the Indian monsoon circulation under past and present-day conditions. The model is driven at the lateral and lower boundaries by the atmospheric output fields of the global coupled Earth system model ECHAM5JSBACH/MPIOM for 44-years-long time slices during the mid-Holocene and the preindustrial present-day climate. Simulations with a horizontal resolution of $50 \mathrm{~km}$ are carried out to analyze the regional monsoon patterns under different external solar forcing and climatic conditions. The focus is on the investigation of the HIRHAM simulated summer monsoon circulation and the comparison of the regional atmospheric circulation and precipitation patterns between the paleo- and the preindustrial climate. Due to mid-Holocene changes in the atmospheric circulation with a reduced and southward shifted monsoonal flow across Arabian Sea and Bay of Bengal, an increase of summer rainfall at the windward slopes of western and southern Himalayas as well as over southern India and decreased rainfall over central India appear which is in agreement with proxy-derived precipitation reconstructions. During the mid-Holocene as well as for the present-day climate the same driving mechanisms for the summer monsoon in extreme wet monsoon years related to regional SST anomalies in the Indian Ocean and convective processes can be verified. Positive (negative) SST anomalies in the northern Indian Ocean enhance (inhibit) the local convection associated with a deepening (weakening) of the low pressure and trigger wet (dry) rainfall anomalies.
\end{abstract}

Keywords: Mid-Holocene, present-day, Indian Summer Monsoon, Regional Climate Model, extreme rainfall, reconstructions.

\section{INTRODUCTION}

In mid-Holocene secular variations of the orbital parameters changed the insolation over the northern hemisphere with a maximum increase of $+35 \mathrm{~W} / \mathrm{m}^{2}$ in summer and a decrease of $-20 \mathrm{~W} / \mathrm{m}^{2}$ in winter compared to preindustrial present-day climate $[1,2]$. These external changes in incoming solar radiation could exert a strong impact on the global and regional climate. Paleoclimatic reconstructions reveal significant changes in the Asian monsoon intensity during the Holocene. Around 6000 years before present (e.g., [3, 4]) the Indian monsoon penetrated further into the inner domain of the Asian continent implying a wetter climate. Modeling studies related this enhancement of the monsoon to the impact of changing solar summer insolation on climate (e.g., [5-7]). The enhanced annual solar cycle affected a higher meridional temperature gradient between the Eurasian land surface and the Indian Ocean with an intensified cross equatorial monsoonal wind and moisture advection over the Arabian Sea and the Bay of Bengal and

*Address correspondence to this author at the Freie Universität Berlin, Institute for Meteorology, Carl-Heinrich-Becker-Weg 6-10, D-12165 Berlin, Germany; Tel: +49 30838 71149; E-mail: stefan.polanski@met.fu-berlin.de more rainfall in summer. General circulation models of the atmosphere (AGCMs) are often used to simulate the largescale atmospheric circulation and the related monsoon circulation. Owing to the coarse horizontal resolution, global AGCMs are not able to capture regional-scale atmospheric circulation and precipitation processes, which strongly depend on the topography, realistically. Therefore regional climate models (RCMs) are nested in an AGCM to increasethe horizontal resolution for a special area of interest by applying the method of dynamical downscaling. At the lower and lateral boundaries RCMs are driven by global model data or data analysis. Several RCM simulations have been carried out for the Indian monsoon region for presentday which show a good agreement in the general monsoon patterns compared to observations. Furthermore, related to the better horizontal resolution of these models, an added value compared to the driving data can be identified especially in the mountain areas, even if the realistic simulation of rainfall has to be further improved particularly due to the cumulus convection parameterization (e.g., [8$11])$.

In this study the focus is on the analysis of the HIRHAM simulated Indian summer monsoon circulation and the 
comparison of the regional atmospheric circulation and precipitation patterns between the past and the present climate. According to this, the decadal climatology over the 44-years-long time slices and the monsoon behavior in selected wet and dry monsoon years have been investigated and compared between mid-Holocene (called " $6 \mathrm{k}$ ") and present-day (called "0k") climate. After a short introduction of the HIRHAM model, the setup of the model simulations and the reconstructed relative moisture index are presented (Section 2). In Section 3 the simulation results for the atmospheric circulation and the precipitation in summer for the two climatic periods and the driving mechanisms for anomalous rainfall years are analyzed. In addition, the calculated relative annual rainfall anomalies are compared with paleoclimatic reconstructions based on the moisture index. Finally, concluding remarks summarize the main results (Section 4).

\section{MODEL AND RECONSTRUCTIONS}

\subsection{Regional Climate Model HIRHAM}

The regional climate model HIRHAM used in this study has been developed by Christensen et al. [12]. It has been recently adapted to the Asian region by Polanski et al. [11]. The dynamical part of the model is based on the hydrostatic limited-area model HIRLAM (High-Resolution Limited Area Model) [13] with prognostic equations for horizontal wind components, temperature, specific humidity, cloud water content, and surface pressure. The physical parameterizations for radiation, land surface processes, sea surface sea-ice processes, planetary boundary layer turbulence, gravity wave drag, cumulus convection, and large-scale condensation are taken from the general circulation model ECHAM4 [14]. Details of the model dynamics and physics can be found in the given references. The integration domain in the Asian region (see Fig. 1) covers an area between $0^{\circ} \mathrm{N}$ to $50^{\circ} \mathrm{N}$ and $42^{\circ} \mathrm{E}$ to $110^{\circ} \mathrm{E}$, including the high topography of the Tibetan Plateau and the Himalayas as well as the northern Indian Ocean. The model domain includes $110 \times 100$ grid points and a horizontal resolution of $0.5^{\circ}$. The vertical discretization consists of 19 irregularly spaced levels in hybrid $\sigma$-p coordinates from the surface up to $10 \mathrm{hPa}$.

At the lateral and lower boundaries, HIRHAM has been forced by the atmospheric output fields of the coupled global Earth system model ECHAM5-JSBACH/MPIOM (called "ECHAM5"), which has been developed at the Max Planck Institute for Meteorology in Hamburg [15]. The ECHAM5 simulations have been run with a horizontal resolution of $3.75^{\circ}$ and 19 vertical levels in hybrid $\sigma$-p coordinates for 600 years starting in mid-Holocene and preindustrial modern climate [16]. The lateral forcing includes all prognostic variables except the cloud water content. The information from the lateral boundaries is transferred into the model interior by a boundary relaxation [17] in a 10-grid-pointwide boundary zone with boundary data updated 2 times a day every 12 hours. At the lower boundary, ECHAM5 sea surface temperatures have been used and updated daily.

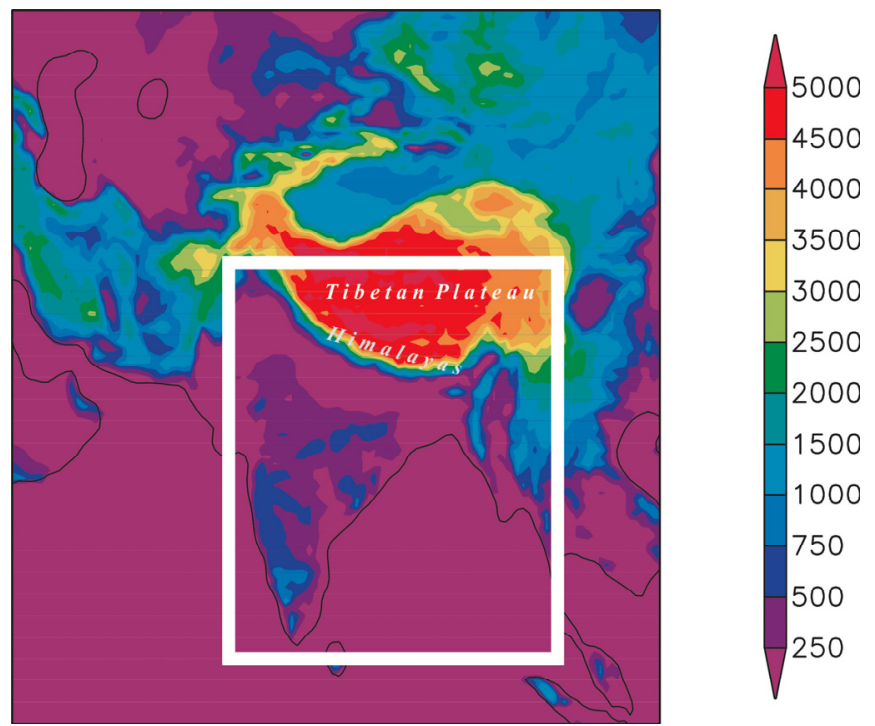

Fig. (1). Integration domain and height of the orography (m; colours) of HIRHAM. Additionally, the monsoon domain is marked by the white box.

According to the ECHAM5 experimental setup, the orbital configurations for $6 \mathrm{k}$ and $0 \mathrm{k}$ are based on Laskar et $a l$. [2]. For both 44-years-long simulations, the composition of greenhouse gases has been set to the preindustrial values concerning PMIP - the Paleoclimate Modelling Intercomparison Project [18] to consider the orbital conditions as single external forcing (see Table 1).

\subsection{Reconstructed Moisture Index}

The HIRHAM simulated rainfall changes between $6 \mathrm{k}$ and 0k are compared with 55 reconstructed paleo-data derived from different archives like lake sediments and cave deposits applying various proxies, which have been collected in the monsoonal regions of Central Asia covering $70^{\circ} \mathrm{E}-130^{\circ} \mathrm{E}$ and $20^{\circ} \mathrm{N}-50^{\circ} \mathrm{N}$ encompassing most parts of China, Mongolia, northern India and Kyrgyzstan [4]. The moisture signals from the separate studies have been translated and synchronized into a qualitative moisture index of a five-part scale: the lowest (highest) value indicates the driest (wettest) intervals for each site since 18000 years. The moisture scales are relative and have been constructed for each 100 year interval during the Holocene period. However, here only the $6 \mathrm{k}$ values were used.

Table 1. Orbital Configurations and Boundary Conditions for HIRHAM Simulations 6k and 0k

\begin{tabular}{|c|c|c|c|c|c|c|}
\hline \multirow{2}{*}{ Experiment } & \multicolumn{3}{|c|}{ Orbital Configurations (Laskar et al., 2004) } & \multicolumn{3}{|c|}{ Greenhouse Gases (PMIP) } \\
\hline & Eccentricity (\%) & Precession $\left({ }^{\circ}\right)$ & Obliquity $\left({ }^{\circ}\right)$ & $\mathrm{CO}_{2}(\mathrm{ppm})$ & $\mathrm{CH}_{4}(\mathbf{p p b})$ & $\mathbf{N}_{2} \mathrm{O}(\mathbf{p p b})$ \\
\hline $0 \mathrm{k}$ & 1.672 & 282.0 & 23.446 & 280 & 760 & 270 \\
\hline
\end{tabular}




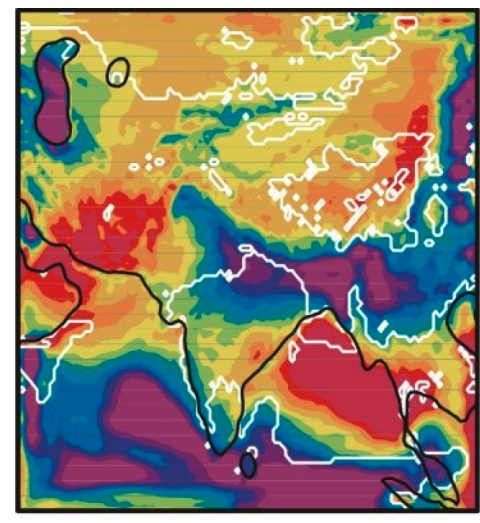

a
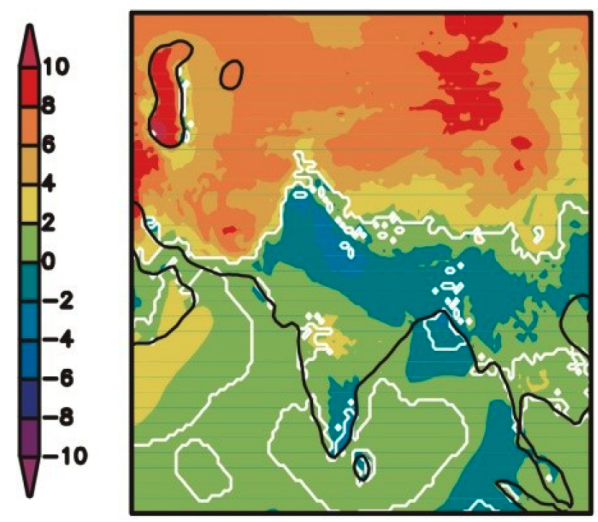

b
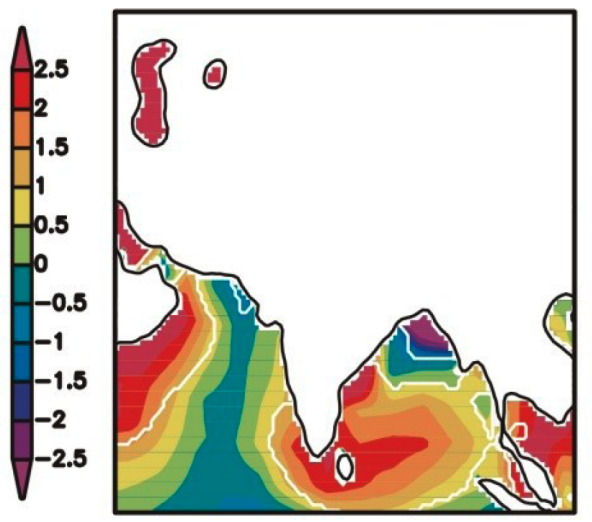

$\mathrm{C}$

Fig. (2). Anomalies of (a) net solar radiation balance at the surface $\left(\mathrm{W} / \mathrm{m}^{2}\right),(\mathbf{b}) 2 \mathrm{~m}$ air temperature $\left({ }^{\circ} \mathrm{C}\right)$ and $(\mathbf{c}) \mathrm{SST}\left({ }^{\circ} \mathrm{C}\right)$ for $\mathrm{HIRHAM}$ " $6 \mathrm{k}$ minus 0k"; summer monsoon (JJAS). The white line represents the areas where the anomalies are statistical significant at the $95 \%$ confidence level.

\section{Climatic ChANGe DURING MID-HOLOCENE SUMMER MONSOON}

\subsection{Variation in Net Radiation and $2 \mathrm{~m}$ Air Temperature Between 6k and 0k}

Fig. (2) describes the changes in the climatic conditions for the summer monsoon season (JJAS) between $6 \mathrm{k}$ and $0 \mathrm{k}$. Shown are the anomalies in net radiation balance at the surface (solar insolation minus thermal emission), $2 \mathrm{~m}$ air temperature and sea surface temperature (SST), simulated by the HIRHAM model. For $6 \mathrm{k}$, the net radiation balance at the surface indicates an increase north of $30^{\circ} \mathrm{N}$, in southwestern Asia and in northern Bay of Bengal of up to $10 \mathrm{~W} / \mathrm{m}^{2}$ implying a stronger diabatic heating in those regions in $6 \mathrm{k}$ compared to $0 \mathrm{k}$. On the other side, a decreased radiation balance during $6 \mathrm{k}$ appears in northern India including the Himalayas. Moreover, positive SST anomalies occur in the western Arabian Sea as well as in the central and southern Bay of Bengal. These changes in the external solar forcing and in the diabatic heating source, which show a statistical significance within a confidence interval of $95 \%$ in most parts, modify the meridional temperature gradient between
Eurasian land surface and the Indian Ocean, particularly due to the warmer Eurasian continent of up to $+2{ }^{\circ} \mathrm{C}$ in $6 \mathrm{k}$. Furthermore, the intensification of the moisture transport towards the continent within the low-level monsoonal wind and the regional rainfall patterns depend on these external forcing mechanisms.

\subsection{Simulated Circulation and Rainfall Changes, and Comparison with Reconstructions}

Changes in the external forcing parameters and in the diabatic heating source have an impact on the circulation and rainfall patterns [7]. In Fig. (3) the mean summer monsoon (JJAS) wind fields at $850 \mathrm{hPa}$ are illustrated for the HIRHAM simulation during $6 \mathrm{k}$ and $0 \mathrm{k}$. For $6 \mathrm{k}$ the model simulates a weakening and southward shift of the nearsurface southwestern monsoonal winds over the Arabian Sea and the Bay of Bengal compared to 0k. These changes in the large-scale summer monsoon circulation influence the precipitation signals in summer statistically significant (see Fig. 3). During 6k, a precipitation increase over southern India and a decrease over central India and the Bay of Bengal occur. Furthermore, the wind circulation during $6 \mathrm{k}$

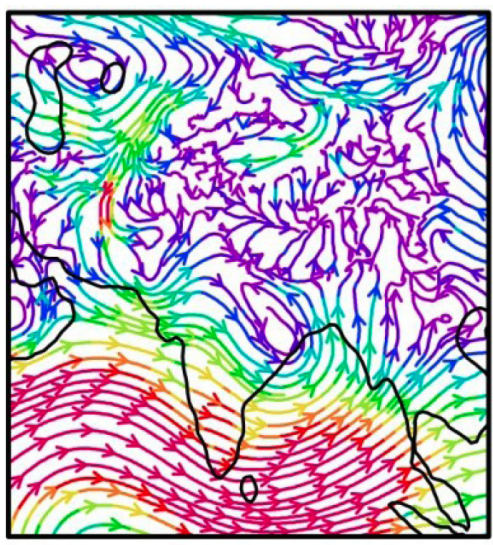

a

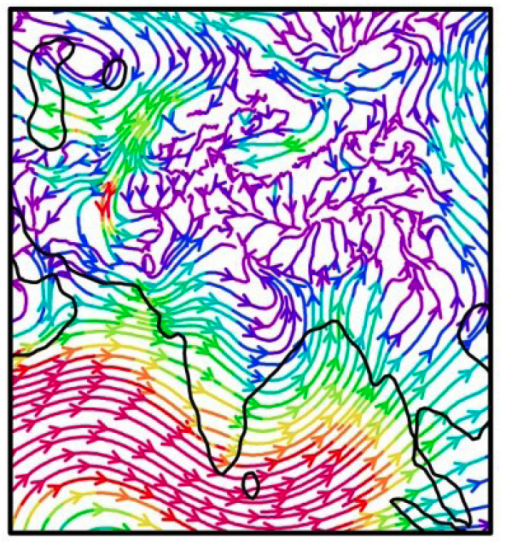

b
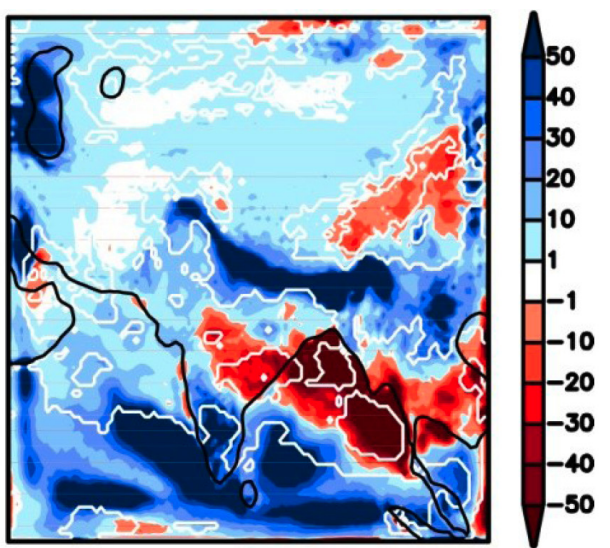

C

Fig. (3). 850-hPa wind fields (streamlines) and wind speed (m/s; colours) for (a) HIRHAM 0k and (b) HIRHAM 6k. (c) Precipitation anomalies (mm; colours) for HIRHAM "6k minus 0k"; summer monsoon (JJAS). The white line in (c) marks the areas where the anomalies are statistical significant at the $95 \%$ confidence level. 
favors an intensification of moisture advection at the windward slopes of the western and southern Himalayas caused by the redirection of the near-surface cross Equatorial Jet over Pakistan [7]. Thus, the uplifting processes are intensified in $6 \mathrm{k}$ accompanied with more rainfall in that region.

Such moisture changes during the Holocene have been described by paleoclimatic reconstructions based on a relative moisture index of Wang et al. [4] (see Fig. 4). The figure compares the HIRHAM simulated relative annual rainfall anomalies and the reconstructed paleoclimatic moisture index. In some areas, especially in northwestern India and along a gradient over central and northeastern Tibetan Plateau, there is a good agreement between the model simulation and the reconstructions. However, the model and the reconstructions disagree in southeastern and eastern parts of the Tibetan Plateau, where the model simulates less rainfall in $6 \mathrm{k}$ while the reconstructions indicate a positive anomaly. These wetter summer climate conditions shown by the moisture index are also reproduced by other global paleoclimate modeling studies especially over East Asia [7, 19]. This is related to different regional atmospheric circulation structures as well as different model physics and parameterization schemes between the HIRHAM model and the global model simulations. Due to the high spatial variability of the moisture signal and reconstruction-inherent uncertainties a higher resolution of paleoclimatic reconstructions would be necessary to better compare model- and proxy-based moisture anomalies.

Fig. (4) further shows that HIRHAM simulates more annual rainfall over the Arabian Sea, the Arabian Peninsula, south to the Caspian Sea and in the western Himalayas during $6 \mathrm{k}$. The most part of annual rainfall is influenced by summer rainfall events. The increase over the Arabian Sea and the surrounding areas is associated with the higher SSTs (see Fig. 2) going along with the enhancement of local convection related to an intensified moisture convergence, a stronger upward motion of moisture and a higher instability in the vertical column of the troposphere [11]. Analogously, the negative rainfall anomalies over northern Bay of Bengal are connected to lower SSTs and a reduction of local convective processes.
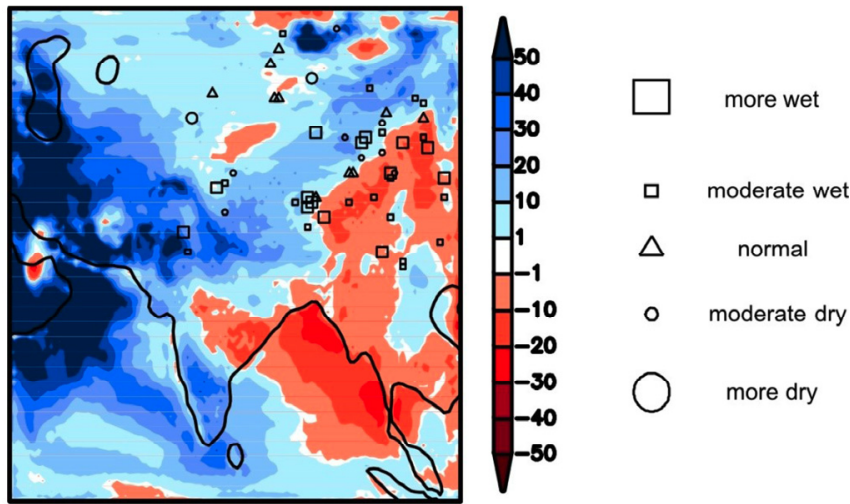

Fig. (4). Annual precipitation anomaly (\%; colours) for HIRHAM " $6 \mathrm{k}$ minus 0k" and reconstructed moisture index (symbols; dimensionless; [4]).

\subsection{Wet and Dry Summer Monsoon Composites}

To further investigate the summer monsoon rainfall changes between $6 \mathrm{k}$ and $0 \mathrm{k}$, typical rainfall anomaly patterns between strong (wet) and weak (dry) monsoon (years) have been analyzed for both time slices. The selection of the anomalous wet and dry composites is done following the criteria of Farrara and $\mathrm{Yu}$ [20]. Monsoon years are defined as anomalous wet (dry), if the summer (JJAS) precipitation

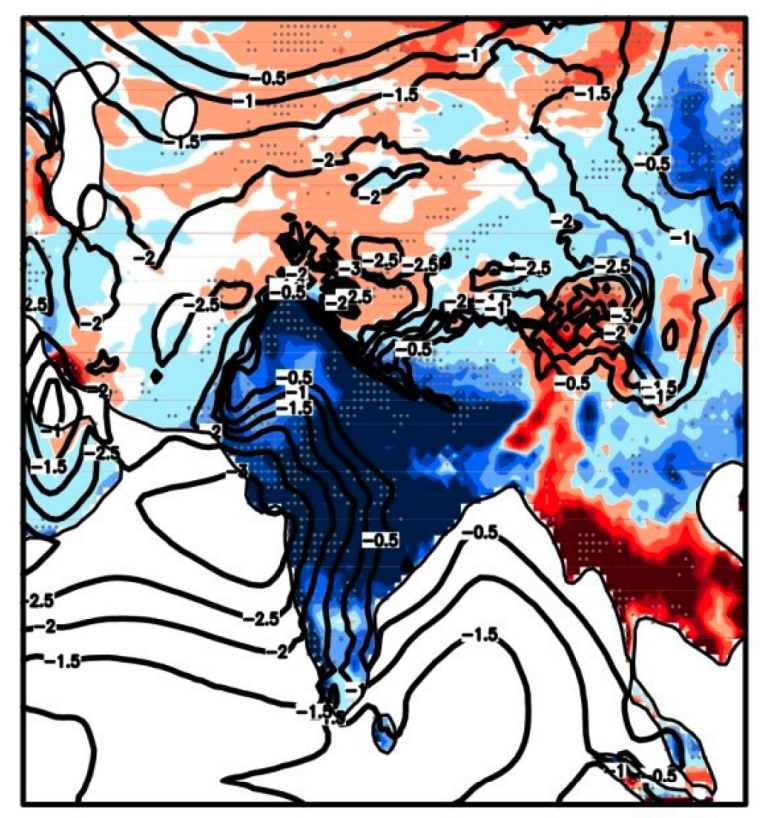

a

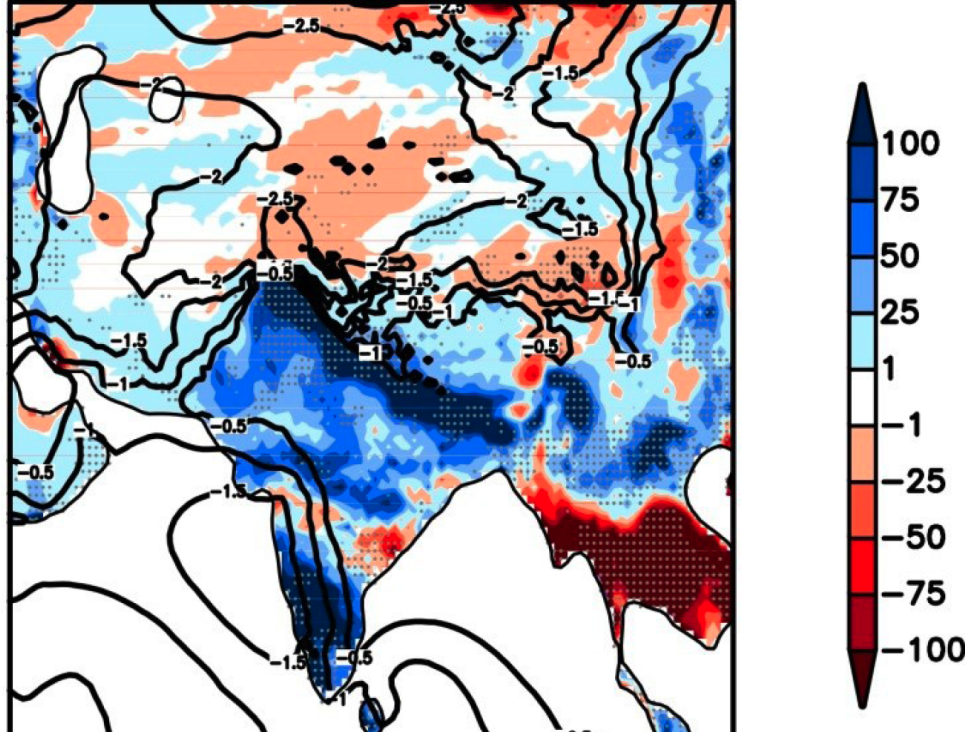

b

Fig. (5). Anomalies of precipitation "wet minus dry" (mm; colours) and mean sea level pressure "wet minus dry" (hPa; contour lines in steps of $0.5 \mathrm{hPa}$ ) for (a) HIRHAM 0k and (b) HIRHAM 6k; summer monsoon (JJAS). The grey dots mark the areas where the anomalies are statistical significant at the $90 \%$ confidence level. 
averaged over the monsoon domain (see Fig. 1) [21] is more (less) than 0.5 standard deviations above (below) the climatological mean.

Fig. (5) shows that during both $6 \mathrm{k}$ and $0 \mathrm{k}$ the spatial large-scale pattern of the precipitation differences "wet minus dry" are quite similar. This is an indication that the driving mechanisms of extreme summer monsoon rainfall are similar in both periods. Particularly similar regional patterns of rainfall anomalies are simulated over the Himalayas and in southeastern Asia. In contrast, for the $6 \mathrm{k}$ time slice the HIRHAM model simulates more rainfall over southern India and in southeastern Himalayas already seen in the summer climatology (see Fig. 3c). Less rainfall in $6 \mathrm{k}$ is estimated over central and northern India. These precipitation anomalies are strongly associated with changes in the atmospheric circulation, which is represented in the figure by the differences in the mean sea level pressure fields (see Fig. 5). In years of strong monsoon during $6 \mathrm{k}$ a southward shift and decrease of the low pressure area from northern Arabian Sea and central India towards southwestern India occurs. This is related to the southward shift of the positive rainfall anomaly "wet minus dry" from central to southern India compared to 0k (see Fig. 5). That shifting low pressure area is statistically significant.

The SST changes over the Indian Ocean (see Fig. 6) are one of the most important drivers for the modified atmospheric circulation and rainfall patterns in wet and dry years. In 0k the pronounced warm SST anomaly in the northern Arabian Sea is associated with intensified local convection. Additionally a depression of the mean sea level pressure field in that region appears during strong monsoon years, which impacts on the simulated wet rainfall anomalies over northern and central India. In contrast, cold SST anomalies in the southern Arabian Sea inhibit the local convection and weaken the near-surface depression with the consequence of a drier southern India. The same spatial SST anomaly pattern occurs during 6k. The warm SST "wet minus dry" anomaly over northern Arabian Sea again drives consistent positive, but smaller rainfall anomalies over the Himalayas and in the Gangetic Plains. Compared to 0k, in $6 \mathrm{k}$ a slightly colder, but not statistically significant, SST anomaly has been simulated in the northern Bay of Bengal, which increases the mean sea level pressure and causes the smaller rainfall amounts in Bangladesh, in southeastern Asia and in central India.

The white dots in Fig. (7) indicate that the wet rainfall anomalies, described in Fig. (5), are related to those regions, which represent the areas of strongest convective activity over land areas associated with a strong moisture convergence shown as positive anomalies "Precipitation minus Evaporation" as well as a strong upward motion in the middle troposphere at $500 \mathrm{hPa}$. This relationship is approved for both $6 \mathrm{k}$ and $0 \mathrm{k}$. In $6 \mathrm{k}$ the strongest convective activity during wet years occurs over the central and eastern Himalayas as well as over southern India. In 0k a large area of convective activity over India is simulated, which is reduced in $6 \mathrm{k}$ as a result of the shifted atmospheric circulation patterns.

The analysis confirms that the summer monsoon rainfall in years between strong and weak monsoonal activity is driven by the SST, the local convective activity and the atmospheric circulation [11, 22-24]. These same mechanisms are identified here in $6 \mathrm{k}$ as well as in $0 \mathrm{k}$. Changes in the distribution of rainfall anomalies "wet minus dry" can be attributed to shifting regional atmospheric circulation patterns driven by modified regional SST anomalies in the Indian Ocean. The convection over land surface areas is driven by large-scale moisture advection from the Indian
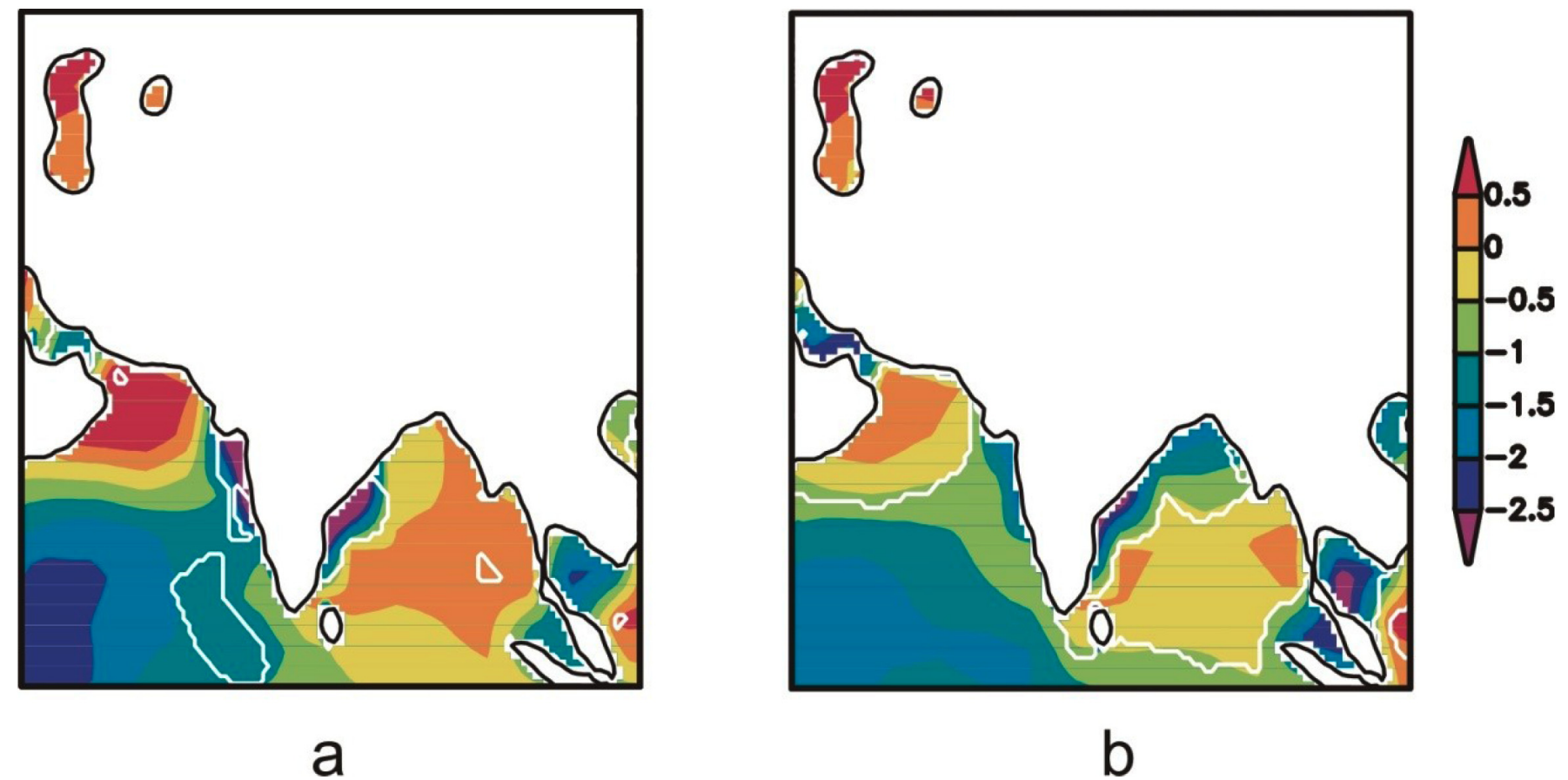

Fig. (6). SST anomalies "wet minus dry" $\left({ }^{\circ} \mathrm{C}\right)$ for (a) HIRHAM 0k and (b) HIRHAM 6k; summer monsoon (JJAS). The white line represents the areas where the anomalies are statistical significant at the $95 \%$ confidence level. 

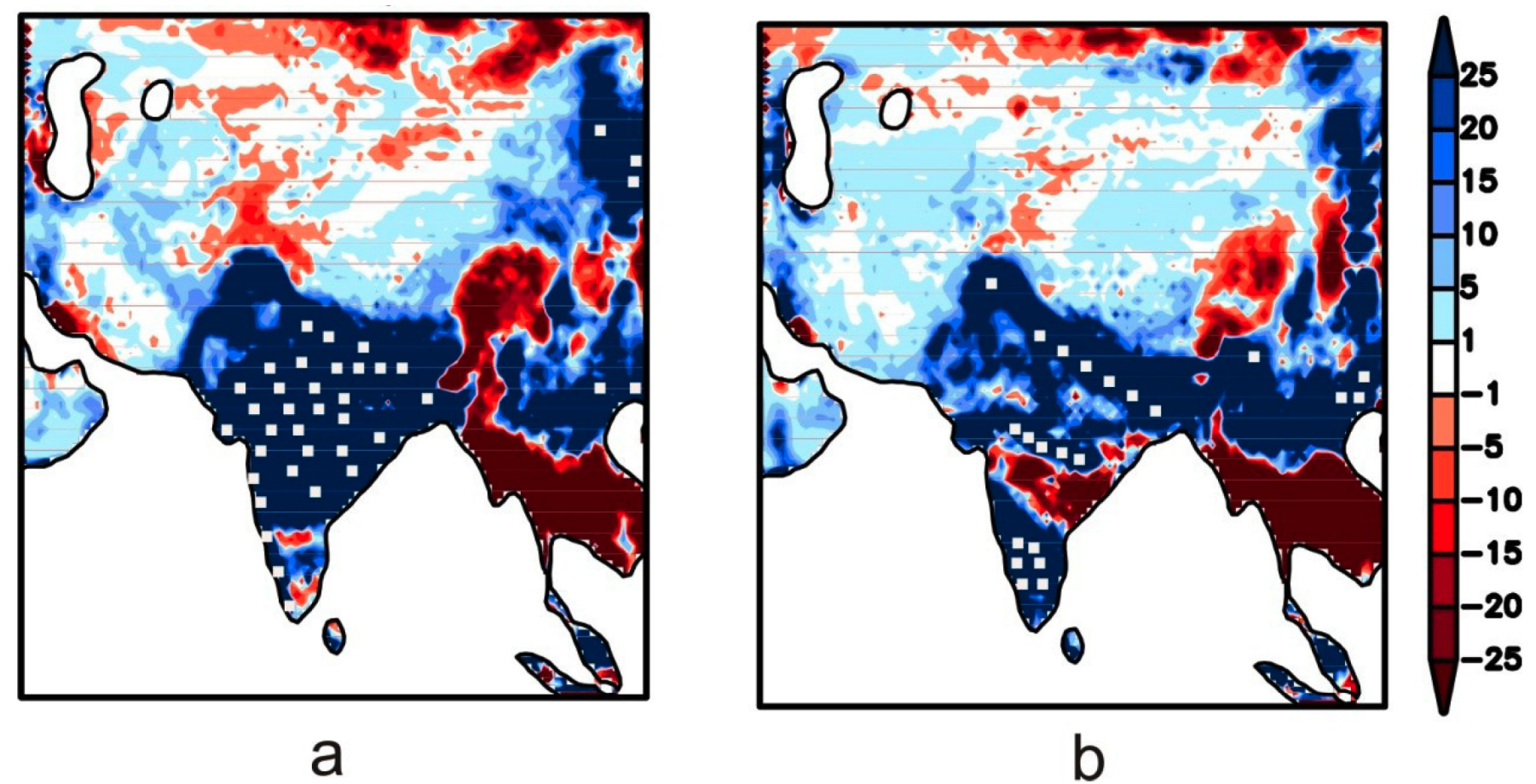

Fig. (7). Anomalies of Precipitation minus Evaporation (P-E) "wet minus dry" (mm; colours) for (a) HIRHAM 0k and (b) HIRHAM 6k; summer monsoon (JJAS). The white dots mark the areas with positive anomalies in both P-E and vertical velocity $(\omega)$ at $500 \mathrm{hPa}$.

Ocean and a strong upward motion of water vapor over land related to enhanced instability and moisture convergence.

\section{CONCLUSIONS}

A paleoclimatic experiment with 44-years-long simulations for the mid-Holocene $(6000$ years before present; $6 \mathrm{k})$ and the preindustrial modern climate (0k) has been used to investigate precipitation and atmospheric circulation changes and to analyze the driving mechanisms of the extreme Indian summer monsoon years. Significant external changes in the solar radiation during mid-Holocene influenced the Asian regional climate as well as the monsoon intensity. Differences in the large-scale atmospheric circulation fields induced regional circulation changes and an increase of summer rainfall over southern India and a decrease over central India and the Bay of Bengal according to a southward shift and decreasing wind in the lower troposphere. Due to the redirection of the near-surface Cross Equatorial Jet over Pakistan, in 6k more rainfall had been calculated over the windward slopes of the western and southern Himalayas compared to 0k. A comparison with paleoclimatic reconstructions based on a moisture index [4] had shown that over the central and northeastern Tibetan Plateau and in northwestern India a good agreement between the simulated and reconstructed annual rainfall anomalies "6k minus 0k" exists. However, a disagreement was found over the eastern and southeastern Tibetan Plateau, where the model simulates drier and the proxies reconstruct wetter conditions in $6 \mathrm{k}$. To evaluate the highly regional-scale rainfall patterns based on paleoclimatic reconstructions, especially associated with the mountains, a better spatial resolution of proxy data is needed.
Anomalous strong (wet) and weak (dry) monsoon (years) are strongly influenced by both dynamical (atmospheric circulation) and thermal changes (SST). During strong monsoon years in $6 \mathrm{k}$ a southward shift and decreased low pressure area from northern and central Arabian Sea towards southwestern India occurred. This was related to a southward shift of the wet rainfall anomaly from central to southern India. In $6 \mathrm{k}$ as well as in $0 \mathrm{k}$ the same driving mechanisms for the summer monsoon in extreme wet monsoon years related to SST anomalies in the Indian Ocean could be verified. Positive (negative) SST anomalies enhanced (inhibited) the local convection with a deepening (weakening) of the low pressure area and finally wet (dry) rainfall anomalies.

\section{ACKNOWLEDGEMENTS}

This research was supported by the DFG-Graduate School 1364/1 "Interactions between Tectonics, Climate and Biosphere in the African-Asian monsoonal region" of the University of Potsdam funded by the German Science Foundation (DFG). The authors thank Manfred Strecker, acting representative of this Graduate School for his permanent support and fruitful discussions. The ECHAM5 boundary data had been supplied by the Max Planck Institute for Meteorology Hamburg. The authors thank Anne Dallmeyer for data transfer and many useful advices and Juliane Otto for running the ECHAM5 simulations. The authors also thank Sabine Erxleben and Ines Hebestadt for advice in the regional climate model simulations and acknowledge the helpful advices of three anonymous reviewers, who improved and clarified the manuscript. 


\section{CONFLICT OF INTEREST}

Declared none.

\section{REFERENCES}

[1] Lorenz SJ, Lohmann G. Acceleration technique for Milankovitch type forcing in a coupled atmosphere-ocean circulation model: method and application for the Holocene. Climate Dynamics 2004; 23 (7-8): 727-43.

[2] Laskar J, Robutel P, Joutel F, Gastineau M, Correia ACM, Levrard B. A long-term numerical solution for the insolation quantities of the Earth. Astronomy Astrophys 2004; 428: 261-85.

[3] Herzschuh U. Palaeo-moisture evolution in monsoonal Central Asia during the last 50.000 years. Quaternary Sci Rev 2006; 25 (1/2): 163-78.

[4] Wang Y, Liu X, Herzschuh U. Asynchronous evolution of the Indian and East Asian Summer Monsoon indicated by Holocene moisture pattern in monsoonal central Asia. Earth-Science Rev 2010; 103: 135-53.

[5] Kutzbach JE, Otto-Bliesner B. The sensitivity of the African-Asian monsoonal climate to orbital parameter changes for $9000 \mathrm{yr} \mathrm{BP}$ in a low resolution general circulation model. J Atmos Sci 1982; 39 (6): 1177-88.

[6] Harrison SP, Jolly D, Laarif F, et al. Intercomparison of simulated global vegetation distributions in response for $6 \mathrm{kyr}$ BP orbital forcing. J Climate 1998; 11: 2721-42.

[7] Dallmeyer A, Claussen M, Otto J. Contribution of oceanic and vegetation feedbacks to Holocene climate change in monsoonal Asia. Climate Past 2010; 6 (2): 195-217.

[8] Bhaskaran B, Jones RG, Murphy JM, Noguer M. Simulations of the Indian summer monsoon using a nested regional climate model: domain size experiments. Climate Dynamics 1996; 12 (9): 573-87.

[9] Dobler A, Ahrens B. Analysis of the Indian summer monsoon system in the regional climate model COSMO CLM. J Geophys Res 2010; 115 (16).

[10] Ratnam JV, Giorgi F, Kaginalkar A, Cozzini S. Simulation of the Indian monsoon using the RegCM3-ROMS regional coupled model. Climate Dynamics 2008; 33 (1): 119-39.
[11] Polanski S, Rinke A, Dethloff K. Validation of the HIRHAMSimulated Indian Summer Monsoon Circulation. Adv Meteorol 2010; 2010: 14 .

[12] Christensen JH, Christensen OB, Lopez P, van Meijgaard E, Botzet M. The HIRHAM4 regional atmospheric climate model. DMI Scientific Report 96-4, Danish Meteorological Institute 1996: p. 51.

[13] Machenhauer B. The HIRLAM final report. HIRLAM Technical Report 5, Danish Meteorological Institute 1998: p. 116.

[14] Roeckner E, Arpe K, Bengtsson L, et al. The atmospheric general circulation model ECHAM-4: Model description and simulation of present-day climate. MPI Report 218, Max-Planck-Institute for Meteorology 1996: p. 90.

[15] Jungclaus JH, Keenlyside N, Botzet M, et al. Ocean circulation and tropical variability in the coupled model ECHAM5/MPI-OM. J Climate 2006; 19 (16): 3952-72.

[16] Otto J, Raddatz T, Claussen M. Climate variability-induced uncertainty in mid-Holocene atmosphere-ocean-vegetation feedbacks. Geophys Res Lett 2009; 36: L23710.

[17] Davies HC. A lateral boundary formulation for multilevel prediction models. Q J R Meteorol Soc 1976; 102: 405-18.

[18] Joussaume S, Taylor KE. Status of the Paleoclimate Modeling Intercomparison Project (PMIP), In: Gates WL, Ed., Proceedings of the First International AMIP Scientific Conference. World Meteorological Organization 1995: 425-30.

[19] Wang T, Wang H, Jiang D. Mid-Holocene East Asian summer climate as simulated by the PMIP2 models. Palaeogeogr Palaeoclimatol Palaeoecol 2010; 288 (1-4): 93-102.

[20] Farrara JD, Yu J.-Y. Interannual Variations in the Southwest U.S. Monsoon and Sea Surface Temperature Anomalies: A General Circulation Model Study. J Climate 2003; 16 (11): 1703-20.

[21] Goswami BN, Xavier PK. ENSO control on the south Asian monsoon through the length of the rainy season. Geophys Res Lett 2005; 32 (18): 4 .

[22] Bhalme HN, Mooley DA. Large-scale Droughts/Floods and Monsoon Circulation. Monthly Weather Rev 1980; 108: 1197-211.

[23] Krishnamurti TN, Bedi HS, Subramaniam M. The Summer Monsoon 1987. J Climate 1989; 2: 321-40.

[24] Krishnan R, Mujumdar M, Vaidya V, Ramesh KV, Satyan V. The Abnormal Indian Summer Monsoon 2000. J Climate 2003; 16: 1177-94. 